\title{
Giant adrenal myelolipoma treated by laparoscopic excision: A case report and review of literature
}

\author{
Veda Murthy Reddy Pogula ${ }^{1}$, Ershad Hussain Galeti ${ }^{1}$, Kashinath Vasanth Thakare ${ }^{1}$, Venkatesh Velivela ${ }^{1}$, Sandeep Reddy ${ }^{1}$, \\ Abhiram Verma ${ }^{1}$, Ayesha Galeti ${ }^{2}$
}

Cite this article: Pogula VMR, Galeti EH, Thakare KV, Velivela V, Reddy S, Verma A, Galeti A: Giant adrenal myelolipoma treated by laparoscopic excision: A case report and review of literature. Ann Urol Oncol 2021; 4(2): 62-68. https://doi. org/10.32948/auo.2021.12.29

\begin{abstract}
Adrenal myelolipoma is inevitably a benign neoplasm of the adrenal gland. It is the second most common primary adrenal incidentaloma after adrenocortical adenomas. Adrenal myelolipoma is a rare, benign and non-functional neoplasm, composed of mature adipose and hematopoietic tissue which closely resembles bone marrow. Most of these lesions are small, unilateral and asymptomatic, discovered incidentally at autopsy or on imaging studies performed for other reasons. We report a case of this rare tumour in a 46-year-old obese male who had presented with vague abdominal pain on the right side past 6 months without any other significant history. Ultrasound and subsequently CECT scan abdomen showed a large well-circumscribed mass arising from the right adrenal gland, measuring $11 \times 10 \mathrm{~cm}$. Laparoscopic right adrenalectomy was performed.
\end{abstract}

Key words Adrenal gland, Adrenal myelolipoma, Incidentaloma, Laparoscopic adrenalectomy

\footnotetext{
1. Department of Urology, Narayana medical college, Nellore, Andhra Pradesh, India.

2. Department of Pathology, Narayana medical college, Nellore, Andhra Pradesh, India.

Correspondence: Ershad Hussain Galeti (Department of Urology, Narayana medical college, Nellore, Andhra Pradesh, India; Email: dr.ershadhussain@ gmail.com)
} 


\section{Introduction}

In 1905, Gierke first described adrenal myelolipoma and the term adrenal myelolipoma was first used by Oberling in the year 1922 [1]. It is a rare tumour with an incidence of $0.08-0.2 \%$ [2]. They have an incidence of $1.4-9 \%$ at autopsy and $0.6-1.3 \%$ on abdominal computed tomography (CT) studies [3]. According to the literature, Myelolipomas account for approximately 3 to $5 \%$ of all primary adrenal tumours [4]. Its incidence jumped from $0.08-0.2 \%$ to 10 $15 \%$ of all adrenal tumours in the last 2 decades. However, its aetiology is still unknown [5]. Most adrenal myelolipomas are small $(<5 \mathrm{~cm})$ and are asymptomatic. Both males and females appear to be equally affected by this tumour which is commonly found between the 50 to 70 age group [6]. The tumour is composed of fat and myeloid tissue and is listed in the group of mesenchymal and stromal tumours of the adrenal cortex according to the latest update of the World Health Organization on endocrine tumours [1]. Occasionally acute haemorrhage within these myelolipomas can result in the sudden onset of pain and hypotension. Myelolipomas that spontaneously haemorrhage is usually $>10 \mathrm{~cm}$. No malignant potential is associated with these lesions $[8,9]$. As commonly being an asymptomatic tumour with accidental discovery and markedly variable sizes, few cases have been reported with biochemical functions [10]. Rarely, myelolipomas have also been reported in extra-adrenal sites like mediastinum [11], spleen [12], kidney [13], bones [14], thorax [15], nasal cavity [16], extradural sites[17] or in the eyes [18]. Ultrasound (US), computed tomography (CT) imaging helps to demonstrate the characteristic imaging features of these tumours, making surgical resection unnecessary in the majority of the cases [19]. Computed tomography (CT) imaging studies show macroscopic fat and calcification with heterogeneous echogenicity due to a non-uniform architecture. On imaging, myelolipomatous lesions tend to fall into one of the three clinicopathologic patterns: (1). isolated adrenal myelolipomas, (2). Myelolipoma with haemorrhage (mean diameter $>10 \mathrm{~cm}$ ), and (3). Myelolipomatous foci within other adrenal pathologic conditions [20]. Myelolipoma is defined as 'giant' when its greatest diameter is $>10 \mathrm{~cm}$. Open radical surgery is the standard treatment of choice for giant myelolipomas, while the minimally invasive approach has been used in only a few cases, which is a rare clinical occurrence [21]. Herein we report a incidental diagnosis of giant isolated adrenal myelolipoma in a 46-year-old male who presented with vague right upper abdominal pain, review the literature and management. To the best of our knowledge, this is the largest adrenal myelolipoma treated with laparoscopic surgery reported in the southern part of India.

\section{Case presentation}

A 46-year-old obese male (BMI- $35 \mathrm{~kg} / \mathrm{m} 2$ ) came with complaints of vague discomfort on the right upper abdomen. The physical examination was unremarkable. Laboratory investigations, which included full blood count, urea and electrolytes, and liver function tests, were within normal range. Ultrasound abdomen showed a well defined homogenously hyperechoic mass measuring approximately $11 \times 9 \mathrm{~cm}$ in size at the upper pole of the right kidney. The right kidney and adjacent liver parenchyma were normal. A CECT (contrast-enhanced computed tomography) scan of the abdomen was done to further evaluate the mass which revealed a well defined, nonenhancing hyperdense solid lesion measuring approximately $11.5 \times 10.2 \mathrm{~cm}$ which has a $-90 \mathrm{HU}$ value (Figure 1a and $\mathbf{1 b}$ ) in the right suprarenal region with diagnosis as adrenal myelolipoma. The right kidney showed normal enhancement. No infiltration of mass into the superior pole of the right kidney or adjacent liver parenchyma. Adrenal mass investigations were done which included 24 hours urinary normetanephrines: 422.5 $\mu \mathrm{g} / 24$ hours (reference range $<600 \mu \mathrm{g} / 24$ hours) and urinary metanephrines: $3.4 \mu \mathrm{mol} / 24 \mathrm{~h}$ (reference range up to $5.5 \mu \mathrm{mol} / 24 \mathrm{~h}$ ) were within normal limits suggesting non-functioning nature of the adrenal mass. Laparoscopic transperitoneal right adrenalectomy was performed. He was positioned in the left semi-lateral position with elevated kidney rest. Four ports were designated at the right side of the abdomen. Two $10-\mathrm{mm}$ ports were created in the right mid clavicular line, below one was for the laparoscopic camera and the upper one was for the main working trocar. Another two 5-mm ports were created, the upper one was just below the xiphisternum for liver retraction and the second one was at the anterior axillary line two inches below the level of the camera port for the other main working trocar (Figure 2a). The procedure steps were carried out as creation of pneumoperitoneum, introduction of the trocars was difficult due to high body mass index, incision of the posteriorperitoneum, and reflection of the intestine. Dissection of the mass was achieved, but, it was technically demanding, especially, medially for the adrenal vein along the inferior vena cava as the tumor was overlapping, superiorly from the liver was difficult as reaching the lap instruments high upto the superior border of the tumor, and posteriorly from the abdominal wall. However, the mass was completely separated from the right kidney (Figure 2b). A plastic bag was placed inside the abdomen through the $10-\mathrm{mm}$ port and the mass was placed into the bag; then the bag was held with a grasper placed through the $5 \mathrm{~mm}$ port and was brought to the right iliac fossa region. The mass was easily delivered through a $4 \mathrm{~cm}$ right iliac fossa incision. The procedure was completed in about 110 min without significant blood loss (100 $\mathrm{ml}$ ) or complications. Post-operative course was uneventful and the patient was discharged on the 4th postoperative day. On gross examination, the specimen was a globular mass measuring $13 \times 11$ $\mathrm{cm}$ and weighing 220 gms. The external surface was smooth, greyish-brown in colour. The cut surface was dark brown with yellowish areas (Figure 3a and 3b). Histopathological examination revealed adrenal tissue at the periphery beneath which was seen a mass composed of varying proportions of adipose tissue with intervening areas of mature and immature hematopoietic tissue with slightly increased megakaryocytic elements confirming the diagnosis of adrenal myelolipoma (Figure $4 \mathbf{a}$ and $\mathbf{4 b}$ ).

\section{Discussion}

Adrenal myelolipomas are composed of variable proportions of mature adipose tissue and active hematopoietic elements. They are usually discovered incidentally on autopsy, surgery, or as incidentalomas on imaging for other reasons [22]. Adrenal myelolipoma (AML) is the second most common primary adrenal incidentaloma representing $15 \%$ of adrenal incidentalomas. Myelolipomas can rarely appear at other sites of the human body, as well, hence the term extra-adrenal myelolipoma [23]. Adrenal myelolipoma is mostly a unilateral tumour without symptoms of endocrine disorder, with bilateral masses occurring in about $10 \%$ of cases [24]. Tumour size has been reported in the literature from a few millimetres to more than $30 \mathrm{~cm}$, but rarely exceeds $5 \mathrm{~cm}$ [22]. They frequently present between the fifth and seventh decades of life without a predominance in either sex, though there is a greater incidence in the right adrenal gland [25]. The youngest patient was 1 -year-old at the diagnosis, while the oldest was 83 years old [23] . Adrenal myelolipoma exhibit four distinct clinicopathologic patterns: 1. Isolated adrenal myelolipoma, 2. Adrenal myelolipoma with acute haemorrhage, 3. Extraadrenal myelolipoma, 4. Myelolipoma is associated with other adrenal diseases [26]. Hypertension has rarely been attributed to functioning adrenal myelolipoma. More than 400 cases are reported in the literature. The aetiology of myelolipoma is unknown. One theory by D. C. Collins suggests that a myelolipoma represents a site of 

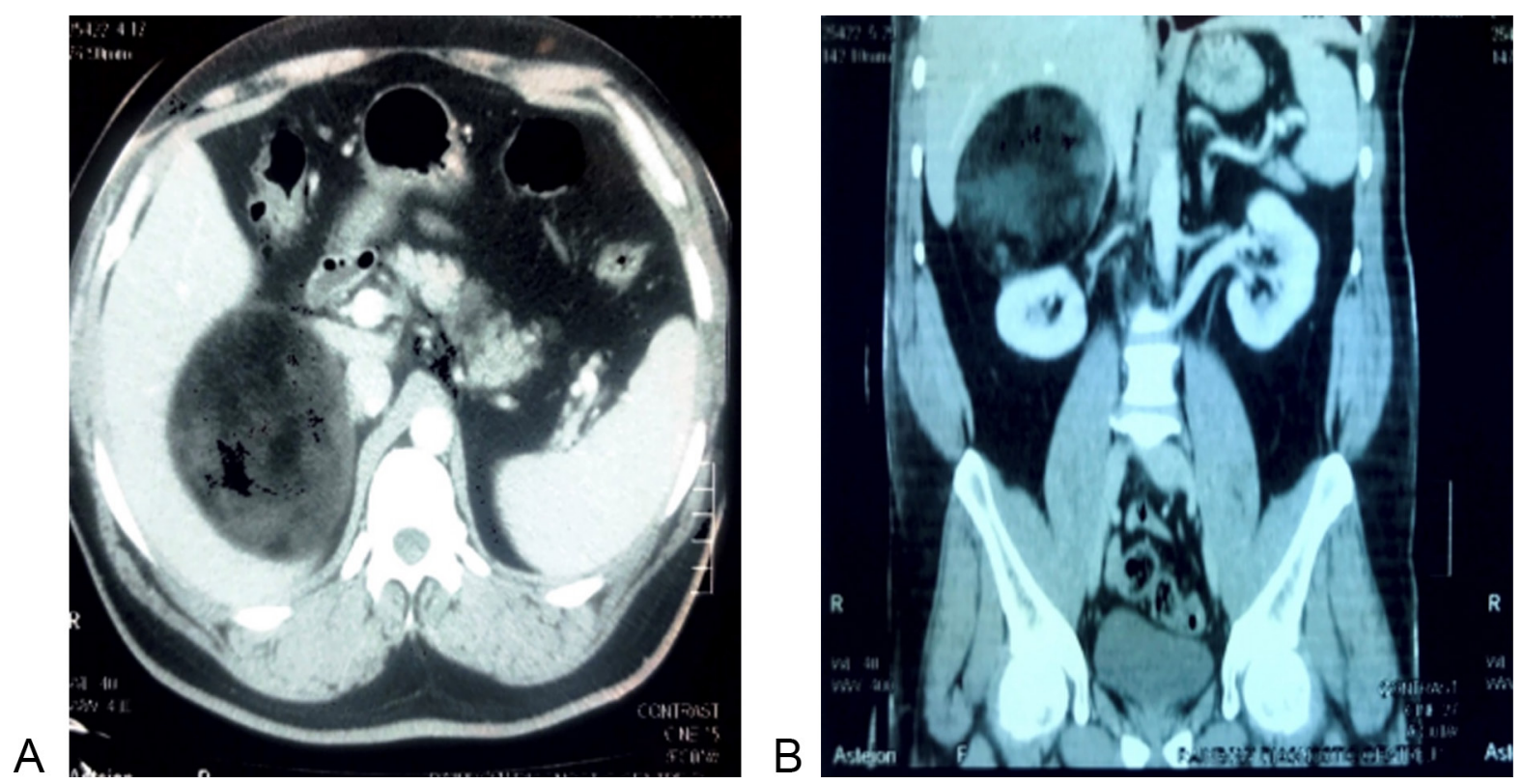

Figure 1. Abdominal CECT. a: Axial view showing a right adrenal heterogenous fatty, well defined, nonenhancing mass with negative attenuation; b: Coronal view showing a right suprarenal mass with heterogenous density having hounsfield units -90 with well-defined margins.

extramedullary haematopoiesis [27]. The most widely accepted theory, as cited by Meaglia and Schmidt in a 1992 study of the natural history of adrenal myelolipoma, is the existence of metaplasia of the reticuloendothelial cells of blood capillaries in the adrenal gland in response to stimuli such as necrosis, infection, stress or long-term ACTH stimulation [28]. Tumorigenesis hypothesises that the fat components are derived by the mesenchymal stem cells of the stromal fat of the adrenal cortex under certain stimuli. Mature adipocytes begin to accumulate and become inflammatory stimulating neighbouring adrenal cortex tissue. During the tumour growth, haematopoietic cells in the central part acquire energy from burning the surrounding fat until they are fully differentiated [29]. Most myelolipomas are asymptomatic and discovered incidentally on abdominal imaging. Some may present with abdominal pain because of huge size or due to haemorrhage or necrosis within the tumour [30] Myelolipomas is rarely manifested by spontaneous retroperitoneal haemorrhage, which remains the most serious complication with mortality of up to $80 \%$ [31]. Transcatheter embolization before surgical resection has been used successfully to achieve haemostasis in cases of ruptured myelolipomas leading to retroperitoneal haemorrhage [32]. Although the tumour itself is non-functioning, there is a $10 \%$ incidence of associated endocrine disorders such as Cushing's disease, Conn's syndrome, diabetes and congenital adrenal hyperplasia. Besides, rare associations with sickle cell anaemia and thalassemia have been reported [33]. The issue of the necessity of hormonal evaluation of AML is debated. In the American Association of Clinical Endocrinologists (AACE) guideline, Zeiger et al. did not propose hormonal evaluation for obvious myelolipoma [34]. The clinical picture should be the major factor in determining the necessity for hormonal work-up [35]. It is very important to differentiate between myelolipomas and other lipomatous adrenal tumours. These masses include adrenocortical adenoma, adrenocortical carcinoma, retroperitoneal liposarcoma, exophytic renal angiomyolipoma, and adrenal lipoma [35] . Ultrasound of the abdomen can differentiate the supra-renal mass from the kidneys, but it cannot confirm a myelolipoma [22]. On CT scans, myelolipomas are well-circumscribed, round or

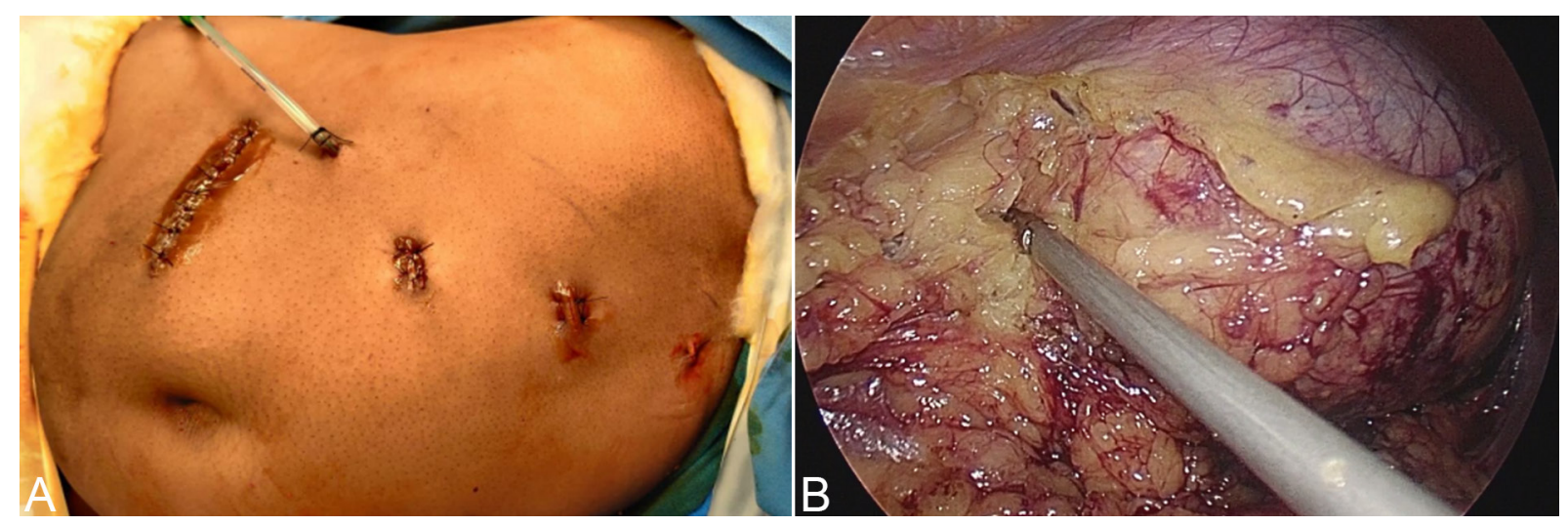

Figure 2. Laparoscopic right adrenalectomy. a: Post-op trocar position scars with drain insitu and right iliac fossa incision for specimen extraction; b: Intraoperative laparoscopic visualisation of a giant right adrenal myelolipoma. 

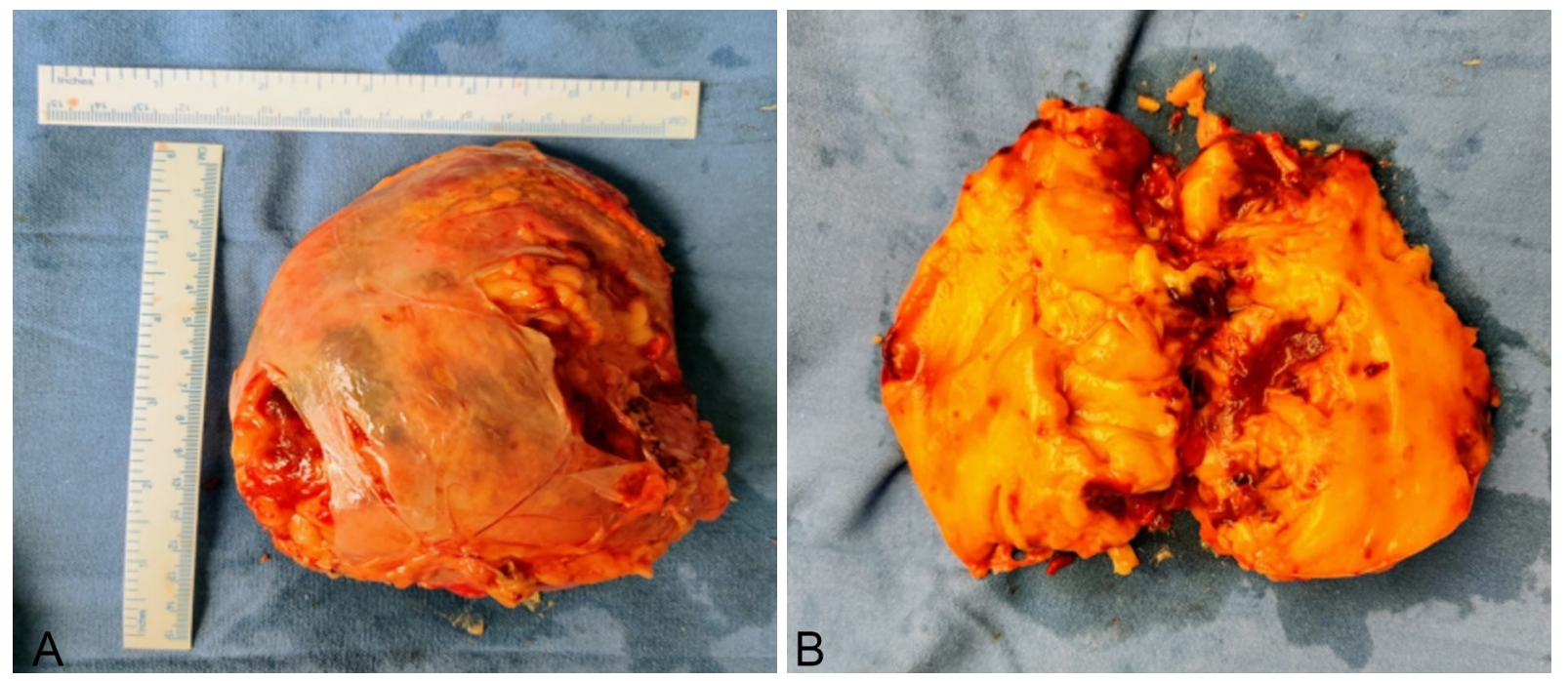

Figure 3. Right adrenalectomy specimen. a: Laparoscopic right adrenalectomy gross specimen; b: Right adrenalectomy cut specimen showing the large yellowish area with area of hemorrhagic necrosis.

elliptical, hypodense and heterogeneous masses. Attenuation values of -120 to $-90 \mathrm{HU}$ are characteristic of the adipose tissue, and the presence of fat density is useful and pivotal in diagnosing the mass as a myelolipoma. Computed tomography was very valuable, where it described the commonly reported characteristic findings suchas the well-demarcated and heterogeneous lowattenuated adrenalmass compressing the surroundings [35, 36] . MRI allows to determine the various structural components of myelolipomas and therefore appears to be a very reliable technique in the diagnosis and characterization of this rare adrenal pathology. [37]. Imaging studies are accurate in diagnosing adrenal myelolipoma is up to $90 \%$ of the cases. Magnetic resonance imaging (MRI) may well characterize the adipose tissue using chemical shift imaging biotechnology. However, this modality seem to be complementary to computed tomography with a little or non-significant additional benefits in most of the instances [36] . If CT shows non-homogenous characteristics or if the diagnosis is in doubt, an image-guided needle biopsy could be performed to confirm the diagnosis, but this approach bears the risk of rupture and bleeding [36]. Daneshm and Quek reviewed the published literature on AM and recommended the removal of lesions $>7 \mathrm{~cm}$ in diameter because of the risk of rupture, although this remains a rare event [38]. The laparotomy or laparoscopy can be performed. Laparoscopic adrenalectomy is safe and effective [23]. Two approaches are applied at laparoscopic surgery, the transperitoneal and retroperitoneal approach. Large tumours can be removed much more easily by the transperitoneal approach than by the retroperitoneal approach. But one approach over the other also does not lead to substantial benefits either to the patients or to the surgeon [39]. The laparoscopic approach may result in minimization of surgical complications and postoperative needs for analgesia and medications, avoidance of generous wound hazards, and shortening of convalescence [40]. Chaudhary et al. reported a case, wherein a $15 \times 11 \mathrm{~cm}$ myelolipoma was removed successfully through a $2.5 \mathrm{~cm}$ incision [10]. In another report, two giant myelolipomas of 11 and $14 \mathrm{~cm}$ were removed without complication by laparoscopic approach [42]. Large tumours can be removed much more easily by the transperitoneal approach than by the retroperitoneal approach [39]. Recently, Shen et al. reported 8 patients with AM who were treated by retroperitoneal laparoscopic liposuction. The mean tumour size was $10.5 \mathrm{~cm}$ and ranged from 8 to $14 \mathrm{~cm}$. Their technique involved making a $1-\mathrm{cm}$ incision on the membrane surface of the AM, suctioning out the lesion under routine suction pressure, and then closing the membrane with a clip [43]. Although no recurrence was observed over 8-77 months of follow-up, no mention was made of whether any residual AM tissue could be seen on follow-up imaging. Whether this technique will have a future role in the surgical approach to AM should await studies in larger numbers of patients with longer follow-up. In the case of bilateral myelolipoma, a staged tumour removal is preferable, removing the larger one and continuing to observe the contralateral myelolipoma as long as possible to avoid adrenal insufficiency and a lifetime of steroid replacement [38]. Generally, the gross features of myelolipoma show yellow areas with the appearance of adipose tissue alternating with hemorrhagic foci composed of bone marrow tissue. The characteristic microscopic appearance of adrenal myelolipoma is composed of bone marrow elements and mature fat. The timing of follow-up was not always declared by the authors. The differential diagnosis for myelolipoma includes lipoma, liposarcoma, angiomyolipoma, retroperitoneal sarcomas, adrenal carcinoma, and adenoma. Myelolipomas are to be differentiated from extramedullary hematopoiesis, which is associated with hepatosplenomegaly, anaemia, infiltrative disease of bone marrow, and skeletal abnormalities. Usually, the follow-up plan consists of a US or CT scan or MRI after 12 and 24 months, but there is no uniformity [44]. Follow-up of giant myelolipomas (diameter $>10 \mathrm{~cm}$ ), however, may be warranted, but the frequency for follow-up is yet to be determined. Being larger than adrenocortical adenomas, follow-up of AMLs by ultrasonography might be feasible.

In compared to open adrenalectomy, there is little question that the laparoscopic technique offers the benefits of avoiding the large wound dangers and having a shorter hospital stay and convalescence. However, there are still certain limitations to this approach, such as obesity, huge tumour sizes, and surgeon expertise. As a result, the greater the surgeon's experience, the higher the tumour sizes that may be handled laparoscopically [45]. Obesity, a big tumour size, and challenging anatomical expansions all posed substantial hurdles in this patient. These challenges, however, were effectively controlled and resolved. Concerns of technical failure and the duration of the process 


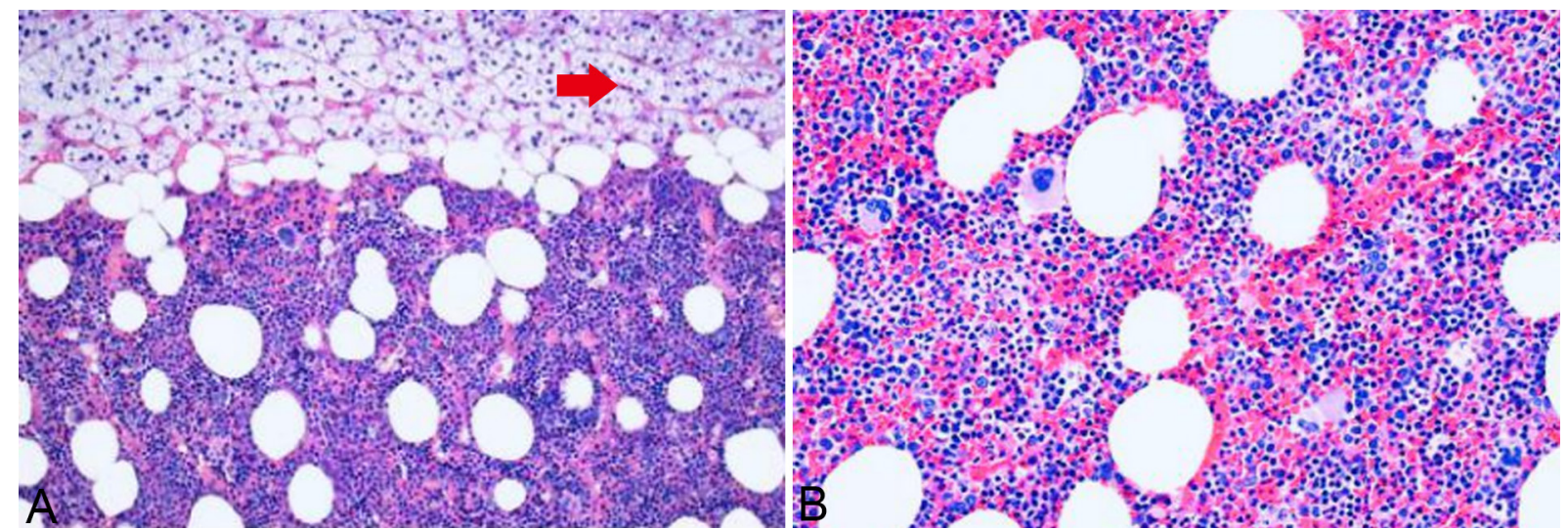

Figure 4a: Hematoxylin and Eosin stain 40x magnification of myelolipoma showing varying proportions adipose tissue admixed with areas of hematopoietic tissue; Figure 4b: Hematoxylin and Eosin stain 40x magnification showing mature adipocytes mixed with areas of hematopoietic tissue containing erythroid, lymphoid, myeloid, and megakaryocytic elements. Red arrow: Normal adrenal Parenchyma.

may arise in the case of large-sized myelolipomas. However, as experience has grown, these fears have gradually subsided. Our case was successfully addressed without the need for open surgery. Furthermore, blood loss during big tumour surgery can be substantial, but laparoscopy offers the benefit of strong hemostasis even with huge tumours. As a result, in our situation, the blood loss was minimal, with no need for transfusion, which might be related to the laparoscopic magnification powers. The feasibility of the laparoscopic method for excision of gigantic adrenal myelolipomas is gradually being established as a viable alternative to the usual open surgical adrenalectomy procedure. However, prudence is still advised for the patients' safety, and the availability of highly trained laparoscopic urologists is suggested.

\section{Conclusion}

Adrenal myelolipomas are uncommon benign tumours comprised of adipose and extramedullary hematopoietic tissue components. They are often asymptomatic and detected incidentally during cross-sectional imaging. Because of enhanced imaging capabilities, giant adrenal myelolipomas are becoming more common. They are frequently seen with effects that are a result of their enormous size. Despite certain technical difficulties, the growing size of huge masses has made laparoscopic excision of giant adrenal myelolipomas in obese individuals appear to be a viable option. The presence of experienced surgeons, on the other hand, may encourage the laparoscopic method to address larger lesions.

\section{Acknowledgements}

We extend our sincere thanks to the patient who participated in the study.

\section{Author contributions}

Conception and design of study: Vedamurthy Reddy;

Acquisition of data: Ershad Hussain Galeti, Kasinath, Sandeep; Analysis and/or interpretation of data: Vedamurthy Reddy, Ershad Hussain Galeti, Venkatesh;

Drafting the manuscript: Ershad Hussain Galeti, Sandeep, Ayesha Galeti;

Revising the manuscript critically for important intellectual content: Vedamurthy Reddy, Ershad Hussain Galeti, Abhiram
Verma.

\section{Competing interests}

No conflict of interest

\section{Funding}

None.

\section{Informed consent}

Written informed consent was obtained from the patient for publication.

\section{Ethical Approval}

Approved by the institutional ethical and research committee.

\section{References}

1. Hong-sheng L, Mei-fu G, Han-song C, \& Shan-qiang H: Adrenal myelolipoma within myxoid cortical adenoma associated with Conn's syndrome. Journal of Zhejiang University SCIENCE B 2008, 9(6): 500-505. https://doi.org/10.1631/jzus.b0720014.

2. Bandurski R, Zaręba K, \& Kędra B: Rare Case of Multifocal (Adrenal and Extra-Adrenal) Myelolipoma. Polish Journal of Surgery 2013, 85(6). https://doi.org/10.2478/pjs-2013-0052.

3. Arnold DT, Reed JB, \& Burt K: Evaluation and Management of the Incidental Adrenal Mass. Baylor University Medical Center Proceedings 2003, 16(1): 7-12. https://doi.org/10.1080/08998280.2003 .11927882 .

4. Kumar U, Priyadarshi S, Tomar V, \& Vohra R: Adrenal myelolipoma with osseous metaplasia and hypercortisolism. Urology Annals 2017, 9(1): 71. https://doi.org/10.4103/0974-7796.198841.

5. Ramirez M, \& Misra S: Adrenal myelolipoma: To operate or not? A case report and review of the literature. International Journal of Surgery Case Reports 2014, 5(8): 494-496. https://doi.org/10.1016/ j.ijscr.2014.04.001.

6. Lam KY, \& Lo CY: Adrenal lipomatous tumours: a 30-year clinicopathological experience at a single institution. Journal of Clinical Pathology 2001, 54(9): 707-712. https://doi.org/10.1136/ jcp.54.9.707.

7. Lam, AKY: Update on Adrenal Tumours in 2017 World Health 
Organization (WHO) of Endocrine Tumours. Endocrine Pathology 2017, 28(3), 213-227. https://doi.org/10.1007/s12022-017-9484-5.

8. Baker M, Blinder R, Spritzer C, Leight G, Herfkens R, \& Dunnick $\mathrm{N}$ : MR evaluation of adrenal masses at $1.5 \mathrm{~T}$. American Journal of Roentgenology 1989, 153(2): 307-312. https://doi.org/10.2214/ ajr.153.2.307.

9. Haaga JR, Dogra VS, Forsting M, Gilkeson RC, Sundaram M. CT and MRI of the whole body: Adrenal glands. 5th ed. Elsevier; 2009, p1838-44.

10. Ramesh J, Jakka N, Venkateshwarlu J, Satyavani N, \& Neelaveni K: Functioning adrenal myelolipoma: A rare cause of hypertension. Indian Journal of Endocrinology and Metabolism 2013, 17(7): 249. https://doi.org/10.4103/2230-8210.119588.

11. Minamiya Y, Abo S, Kitamura M, \& Izumi K: Mediastinal extraadrenal myelolipoma: Report of a case. Surgery Today 1997, 27(10): 971-972. https://doi.org/10.1007/bf02388150.

12. Zeng Y, Ma Q, Lin L, Fu P, Shen Y, Luo Q Y, Zhao LH, Mou JH, \& Xiao HL: Giant Myelolipoma in the Spleen. International Journal of Surgical Pathology 2015, 24(2), 177-180. https://doi. org $/ 10.1177 / 1066896915617027$.

13. Ghaouti M, Znati K, Jahid A, Zouaidia F, Bernoussi Z, \& Mahassin $\mathrm{N}$ : Renal myelolipoma: a rare extra-adrenal tumour in a rare site a case report and review of the literature. Journal of Medical Case Reports 2013, 7(1). https://doi.org/10.1186/1752-1947-7-92.

14. Sundaram M, Bauer T, von Hochstetter A, Ilaslan H, \& Joyce M: Intraosseous myelolipoma. Skeletal Radiology 2007, 36(12): 11811184. https://doi.org/10.1007/s00256-007-0347-x.

15. M Krismann, G Reichle, KM Müller: [Thoracic bilateral myelolipoma]. Pneumologie 1993, 47, 501-503.

16. George SA, Manipadam MT, \& Thomas R: Primary myelolipoma presenting as a nasal cavity polyp: a case report and review of the literature. Journal of Medical Case Reports 2012, 6(1). https://doi. org/10.1186/1752-1947-6-127.

17. Newman SJ, Inzana K, \& Chickering W: Extradural Myelolipoma in a Dog. Journal of Veterinary Diagnostic Investigation 2000, 12(1): 71-74. https://doi.org/10.1177/104063870001200115.

18. Storms G, \& Janssens G: Intraocular myelolipoma in a dog. Veterinary Ophthalmology 2013, 16: 183-187. https://doi.org/10.1111/ vop.12059.

19. Galli L, \& Gaboardi F: Adrenal Myelolipoma: Report of Diagnosis by Fine Needle Aspiration. Journal of Urology 1986, 136(3), 655-657. https://doi.org/10.1016/s0022-5347(17)45006-3.

20. Kenney PJ, Wagner BJ, Rao P, \& Heffess CS: Myelolipoma: CT and pathologic features. Radiology 1998, 208(1), 87-95. https://doi. org/10.1148/radiology.208.1.9646797.

21. Teo XL and Lim SK: Robotic assisted adrenalectomy: is it ready for prime time? Investig Clin Urol 2016, 57 (Suppl 2): S130-S146.

22. Doddi S, Singhal T, Leake T, \& Sinha P: Management of an incidentally found large adrenal myelolipoma: a case report. Cases Journal 2009, 2(1): 8414. https://doi.org/10.4076/1757-1626-2-8414.

23. Decmann B, Perge P, Tóth M, \& Igaz P: Adrenal myelolipoma: a comprehensive review. Endocrine 2017, 59(1): 7-15. https://doi. org/10.1007/s12020-017-1473-4.

24. Park SY, Kwak MK, Kim HJ, Park HK, Suh KI, Yoo MH, Jin SY, Yun S, \& Byun DW: Case report of a bilateral adrenal myelolipoma associated with Cushing disease. Medicine 2017, 96(52): e9455. https://doi.org/10.1097/md.0000000000009455.

25. D’Addosio R, Rojas J, Bermúdez V, Ledesma F, \& Hoedebecke K: Case Report: An incidentaloma that catches your eye - adrenal myelolipoma. F1000Research 2017, 6: 1140. https://doi.org/10.12688/ f1000research.11766.1.

26. Rao P, Kenney PJ, Wagner BJ, \& Davidson AJ: Imaging and pathologic features of myelolipoma. RadioGraphics 1997, 17(6): 1373-1385. https://doi.org/10.1148/radiographics.17.6.9397452.

27. Suszczyk D, Pawłowska A, Okła K, Parafiniuk K, Polak G, Kotarski $\mathrm{J}$, \& Wertel I: The role of selected populations of immune cells in the pathogenesis of endometriosis. Current Gynecologic Oncology 2018, 16(3): 167-176. https://doi.org/10.15557/cgo.2018.0020.

28. Rajput R, Bhansali A, Khandelwal N, \& Radotra BD: Evolution of Adrenal Myelolipoma in a Patient With Congenital Adrenal Hyperplasia. The Endocrinologist 2007, 17(4): 200-201. https://oi. org/10.1097/ten.0b013e31813e5fle.

29. Feng C, Jiang H, Ding Q, \& Wen H: Adrenal myelolipoma: A mingle of progenitor cells? Medical Hypotheses 2013, 80(6): 819-822. https://doi.org/10.1016/j.mehy.2013.03.021.

30. Liu N, Zhang W, Tan J, Zhou J, Yu X, Ren N, Fang Z, Jiao W, Fan Y, \& Liu C: Adrenal myelolipoma with hyperandrogenemia and schizophrenia. Cancer Management and Research 2018, Volume 10: 177-180. https://doi.org/10.2147/cmar.s145332.

31. Mhammedi WA, Ouslim H, Ouraghi A, Irzi M, Elhoumaidi A, Elhoumaidi A, Chennoufi M, Mokhtari M, Elmouden A, \& Barki A: Adrenal myelolipoma: from tumorigenesis to management. Pan African Medical Journal 2019, 34. https://doi.org/10.11604/ pamj.2019.34.180.20891.

32. HISAMATSU H, SAKAI H, TSUDA S, SHIGEMATSU K, \& KANETAKE H: Combined adrenal adenoma and myelolipoma in a patient with Cushing's syndrome: Case report and review of the literature. International Journal of Urology 2004, 11(6): 416-418. https://doi.org/10.1111/j.1442-2042.2004.00815.x.

33. Kumar S, Jayant K, Prasad S, Agrawal S, Parma KM, Roat R \& Kumar K: Rare Adrenal Gland Emergencies: A Case Series of Giant Myelolipoma Presenting With Massive Hemorrhage and Abscess. Nephro-Urology Monthly 2038, 7(1). https://doi.org/10.5812/ numonthly.22671.

34. Zeiger MA, Thompson GB, Duh Q Y, Hamrahian AH, Angelos P, Elaraj D, Fishman E, Kharlip J, Hamrahian AH, Garber JR, Mechanick JI, Demeure MJ, \& Inabnet WB: American Association of Clinical Endocrinologists and American Association of Endocrine Surgeons Medical Guidelines for the Management of Adrenal Incidentalomas: Executive Summary of Recommendations. Endocrine Practice 2009, 15(5): 450-453. https://doi.org/10.4158/ ep.15.5.450.

35. Decmann B, Perge P, Tóth M, \& Igaz P: Adrenal myelolipoma: a comprehensive review. Endocrine 2017, 59(1): 7-15. https://doi. org/10.1007/s12020-017-1473-4.

36. Thota A, Shankar R, Desai M \& Shenoy V: Adrenal myelolipoma: Controversies in its management. Indian Journal of Urology 2015, 31(2): 94. https://doi.org/10.4103/0970-1591.152807.

37. Boraschi P, Neri E, Braccini G, Gigoni R, Caramella D, Perri G, \& Bartolozzi C: Choledocholithiasis: Diagnostic accuracy of MR cholangiopancreatography. Three-year experience. Magnetic Resonance Imaging 1999, 17(9): 1245-1253. https://doi.org/10.1016/ s0730-725x(99)00075-2.

38. Daneshm and S, Quek ML: Adrenal myelolipoma: diagnosis and management. Urol J. 2006; 3(2): 71-74.

39. Hemal AK, Singh A, \& Gupta NP: Whether adrenal mass more than $5 \mathrm{~cm}$ can pose a problem in laparoscopic adrenalectomy? An evaluation of 22 patients. World Journal of Urology 2008, 26(5): 505508. https://doi.org/10.1007/s00345-008-0270-3.

40. Gershuni VM, Bittner JG, Moley JF \& Brunt LM: Adrenal Myelolipoma: Operative Indications and Outcomes. Journal of Laparoendoscopic \& Advanced Surgical Techniques 2014, 24(1): 8-12. https://doi.org/10.1089/lap.2013.0411.

41. Chaudhary R, Deshmukh A, Singh K, \& Biswas R: Is size really a contraindication for laparoscopic resection of giant adrenal myelolipomas? BMJ Case Reports 2016, bcr2016215048. https://oi. org/10.1136/bcr-2016-215048.

42. Agrusa A, Romano G, Frazzetta G, Chianetta D, Sorce V, di Buono G \& Gulotta G: Laparoscopic adrenalectomy for large adrenal masses: Single team experience. International Journal of Surgery 2014, 12, S72-S74. https://doi.org/10.1016/j.ijsu.2014.05.050.

43. Shen X, Qiu Y, Zheng Y \& Zhang S: Retroperitoneal Laparoscopic 
Liposuction for Large Adrenal Myelolipomas: A Report of Nine Cases. Journal of Laparoendoscopic \& Advanced Surgical Techniques 2012, 22(6): 578-580. https://doi.org/10.1089/ lap.2012.0113.

44. Zattoni D, Balzarotti R \& Rosso R: The management of bilateral myelolipoma: Case report and review of the literature. International Journal of Surgery Case Reports 2015, 12: 31-36. https://doi. org/10.1016/j.jjscr.2015.04.021.

45. Ghatak S, Mridha AR: Laparoscopic resection of a largeadrenal myelolipoma: a case report. Cases J 2009; 2: 9313http://www. casesjournal.com/content/2/1/9313. 